- Kết quả điều trị: Tỷ lệ khỏi hoàn toàn là $91.8 \%$, tử vong 01 trường hợp (7.2\%); kết quả của chúng tôi tương đồng với kết quả của các nghiên cứu khác. Trong nghiên cứu của Nguyễn Gia Bình: tỷ lệ tử vong là $8 \%$; nghiên cứu của Nguyễn Hữu Nhượng thì không ghi nhận trường hợp nào tử vong.[5], [6] Trong nghiên cứu của chúng tôi, trường hợp tử vong là trường hợp nhập khoa muộn (sau chuẩn đoán 01 tuần) và đã rơi vào tình trạng suy đa tạng.

\section{KẾT LUÂN}

Thay huyết tương là môt liêu pháp an toàn và hiệu quả trong phối hợp điều trị viêm tuy cấp do tăng TG; cần được triển khai rộng rãi và thường quy trong bệnh viện.

\section{TÀI LIÊU THAM KHẢO}

1. Haney J.C (2007), "Necrotizing pancreatitis: diagnosis and management", Surg Clin North Am, 87(6): 1431 - 1446
2. Nguyễn Khánh Trạch (2003), "Viêm tuy. cấp", Bệnh học Nội khoa - dành cho đối tượng sau đại hơc tâp 1, Nhà xuất bản Y học, Hà Nôii, tr 143 - 153

3. Yadav D (2003), "Issues in hyperlipidemic pancreatitis", J Clin Gastroenterol, 36(1): 54-62

4. Gubensek J, et al (2009), "Treatment of hyperlipidemic acute pancreatitis with plasma exchange: a single - center experience", Ther Apher Dial, 13 (4): $314-317$

5. Nguyê̂n Gia Bình (2012), " Nghiên cứu đăcc điểm lâm sàng, cận lâm sàng và điêu trị viêm tuỵ cấp do tăng Triglyceride", đề tài cơ sở - Bênh viên Bach Mai

6. Nguyên Hữu Nhượng (2018), "Nhận xét kết quả tháy huyết tương trong điều trị viêm tuy cấp tăng Triglycerid", đề tài cơ sở - Bênh viên 354

7. Đố Thanh Hoà (2019), "Nghiên cứu đặc điểm lâm sàng, cân lâm sàng và hiêu quả của liêuu pháp thay huyêt tương trong điều trị viêm tụy cấp do tăng triglycerid máu", Luân văn tiến sĩ $Y$ học - Viện nghiên cứu Y Dược lầm sàng BV 108

8. Yuchen Wang (2018), "Assessment of the Effects of Plasmapheresis on patients with Hypertriglyceridemia -induced Acute Pancreatitis", Pancreatic Disorders and Therapy, DOI: 10.4172/2165-7092.1000192

\title{
SỬ DỤNG VÍT NEO TRONG TẠO HÌNH GÓC MẮT TRONG: BÁO CÁO TRƯờNG HỢP LÂM SÀNG
}

\author{
Hoàng Tuấn Anh*, Phan Văn Tân*, Nguyễn Họ̣p Nhân*, \\ Nguyễn Ngọc Dương*, Bùi Hữu Phước*
}

\section{TÓM TẮT}

Di lệch góc mắt trong gây ảnh hưởng lớn tới sự hài hòa và thấm mỹ của khuôn mặt, làm biến dạng hê thống dẫn lệ. Đã có nhiều nghiên cứu đề xuất các phương pháp tạo hình cố định lại vị trí dây chằng góc mắt trong. Trong báo cáo này, chúng tôi trình bày hai case lâm sàng tạo hình góc mắt trong sử dụng kĩ thuât tao hình chữ $Z$ để đưa góc mắt về vị trí giải phẩu và sử dụng vít neo để cố định góc mắt. Kết quả phẩu thuật đươợ đánh giá qua chỉ số nhân trắc tỉ lê độ dài hai góc mắt bên bệnh/độ dài hai góc mắt bên lành. Kết quả khả quan của hai case lâm sàng dẫn tới đề xuất sử dụng vít neo trong neo giữ và tạo hình góc mắt trong là phương pháp đơn giản, an toàn, cố định tốt dây chằng góc mắt trong.

Tứ khóa: Dây chằng góc mắt trong, vạt chũ̃ Z, vít neo cùng bên, vít tự tiêu

\section{SUMMARY \\ MEDIAL CANTHOPLASTY USING ANCHOR SCREW: PREMLIMINARY REPORT}

*Trường Đại học Y Hà Nội

Chịu trách nhiệm chính: Hoàng Tuấn Anh

Email: tuananhcmfs@gmail.com

Ngày nhận bài: 24/8/2021

Ngày phản biên khoa hoc: 13/9/2021

Ngày duyệt bài: 30/9/2021
The displacement of the medial canthus greatly interfere facial harmony and disturbs function of the lacrimal system. Multiple techniques have been reported for repositioning the medial canthal tendon. In this article, we present two cases of medial canthoplasty using $\mathrm{Z}$ plasty for repositioning the medial canthus and anchor screws for tendon fixation. The results were evaluated by the standard anthropometric measurement of eyelid aperture: the ratio of the deformity palpebral aperture width site to the normal palpebral aperture width site. The success of the reported cases suggests that the use of anchor srew for medial canthopexy can be considered an easily, safely performed and allowed stable fixation of the medial canthal tendon.

Keywords: Medial canthal tendon, Z flap, anchor screw, absorbable screw

\section{I. ĐĂT VẤN ĐỀ}

Dây chằng góc mắt trong đóng vai trò quan trong về chức năng và thẩm mỹ của mắt, duy trì hình thái và độ mở góc mắt trong trong giới han bình thường, tham gia dẫn lưu nước mắt về hệ thống ống dẫn lệ, ngăn cản tình trạng lộn mi dưới... ${ }^{1}$ Các nguyển nhân gây biến dạng góc mắt trong bao gồm dị tật bầm sinh, chấn thương hàm mặt, cắt bỏ khối u vùng góc mắt, phẫu thuật cần bộc lộ vùng so mặt. Các kĩ thuật tạo 
hình góc mắt trong tập trung vào 3 khía cạnh: lựa chọn đường rạch da, vị trí cố định góc mắt trong và kĩ thuật cố định góc mắt trong. Cố địnnh chắc dây chằng góc mắt tại đúng vị trí giải phẫu để đạt yêu cầu thẩm mỹ, hướng bám của dây chằng, đảm bảo sự cân đối của 2 góc mắt trong và đảm bảo góc mắt trong đi sát nhãn cầu là mục tiêu chính trong quá trình phẫu thuật.Cho tới nay, y văn ghi nhận các báo cáo về các kĩ thuật tạo hình góc mắt trong gồm khâu cố định vào màng xương, cố định bằng chỉ thép xuyên xương mũi, chỉ thép kết hợp lưới ti tan, hệ thống neo góc mắt trong Mitek... tuy nhiên vấn chưa đạt được đồng thuận về phương pháp tối ưu 2,3 . Với mục tiêu đảm bảo chức năng, đạt được sự cân đối về thẩm mỹ và giảm thiểu tối đa biến chứng, chúng tôi lựa chọn phương pháp tạo hình góc mắt trong với kĩ thuật tạo hìnhchữ Z kết hợp cố định bằng vít tự tiêu/titan và chỉ không tiều Prolen 50 thu được kết quả ban đầu đáng khích lệ.
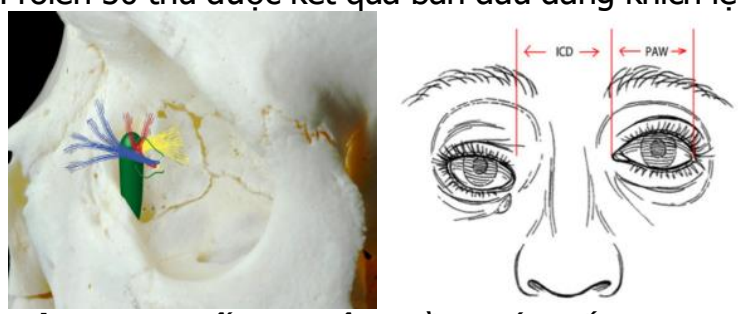

Hình 1. A. Cấu tạo dây chằng góc mắt trong với 2 bó chính trước, sau và 1 bó phụ ${ }^{3}$

B. Đo khoảng cách 2 góc mắt trong và góc mắt trong-góc mắt ngoài. ${ }^{3}$

\section{II. ĐỐI TƯợNG VÀ PHƯƠNG PHÁP NGHIÊN CỨU}

Nghiên cứu được thiết kế dưới dạng chùm case lâm sàng gồm 2 bệnh nhân, 1 bệnh nhân nữ 26 tuổi và 1 bệnh nhân nam 11 tuổi, được phẫu thuật bởi cùng một phẫu thuật viên. 2 bệnh nhân đều bị di lệch góc mắt trong do dị tật bẩm sinh, có tiền sử phẫu thuật nhưng chưa can thiệp vào vùng góc mắt trong. Quy trình phẫu thuật bao gồm các bước:

(1) Xác định vị trí góc mắt mới đối xứng góc mắt trong bền lành qua đường giữa mă̆t, lấy lên cao và vào trong hơn $2 \mathrm{~mm}$ so với vị trí đối xứng góc mắt trong để bù trừ hiện tượng co kéo sau phẫu thuật.

(2) Thiết kế vạt chữ $Z$ để chuyển vị trí góc mắt, bóc tách bộc lộ dây chẳng góc mắt trong và túi lệ. Do vị trí rạch da lệch ngoài so với đường đi của lệ quản trền và lệ quản dưới, ống silicone không được sử dụng để bảo vệ lệ quản.

(3) Sau khi bộc lộ dây chẳng góc mắt trong, bóc tách màng xương bộc lộ vị trí sau trên của hố lệ, là vị trí bắt vít cố định. 1 vít1.5x5mm được sử dụng làm điểm neo cố định. Trước khi vít được cố định vào lỗ khoan trên xương mũi, chỉ Prolene 50 được buộc vào đầu vít với 2 đâu chỉ để chờ, bắt vít kèm chỉ chờ vào vị trí lỗ khoan.

(4) Dây chằng góc mắt trong được khâu cố định vào vít bằng sợi Prolen, hướng iên trên và vào trong, kiểm tra sự đối xứng của 2 góc mắt trước khi khóa chỉ. Cẩm máu kĩ, đóng da 2 lớp bằng chỉ PDS 50 và nilon 70 .

\section{KẾT QUẢ NGHIÊN CỨU}

Kết quả hậu phẫu bệnh nhân 1 (T.T.Q.A) sau 3 tháng và bệnh nhân 2 (N.M.H) sau 1.5 tháng cho thây có sự cải thiện rõ về vị trí góc mắt trong, sử dụng chỉ số tỉ lệ khoảng cách giữa góc mắt ngoài góc mắt trong bên bệnh/bên lành và tỉ lệ khoảng cách góc mắt trong - đường giữa mặt bên bệnh/bên lành (Hình 1B) cho thây sự cải thiện sau mổ, không ghi nhận tình trạng co kéo thứ phát.

Trường hợp lâm sàng 1. Bệnh nhân nữ 26 tuổi, tiền sử u xớ thần kinh nửa mă̆t phải bẩm sinh, đã xạ trị, cắt bỏ một phần khổi u xơ vùng góc hàm dưới phải, tạo hình bằng vạt dưới cằm. Khám góc mắt trong phải di lệch xuống dưới và ra ngoài, tỉ lệ khoảng cáchgiữa góc mắt ngoài góc mắttrong bên bênh/bên lànhlà 0.9063 ,tỉ lệ khoảng cách góc mắt trong - đường giữa mặt bên bệnh/bên lành là 1.2 , nếp mí và cung mày phải cao hơn so với cung mày trái, không ghi nhận hiện tượng lộn mi hay tắc ống dẫn lệ ở mắt phải (Hình $2 A)$, vạt góc hàm phải dày nhẹ. Bệnh nhân được tiến hành tạo hình góc mắt trong phải, ha cung mày phải bằng 2 vít titan, 1 vít treo dây chẳng mắt, 1 vít hạ thấp cung mày(reverse browlift) sửa biến dạng lần mổ trước, làm mỏng vạt ở góc hàm dưới phải.Khám lại sau 3 tháng góc mắt trong phải được cố định lên trên và vào trong, tỉ lệ khoảng cách giữa góc mắt ngoài - góc mắt trong bên bệnh/bên lànhtăng lên 0.9643, ti lệ khoảng cách góc mắt trong - đường giữa mặt bên bệnh/bên lành giảm xuống 1.05, không ghi nhận tình trạng co kéo, tắc hệ thống dẫn lệ, sẹo lồi hay sẹo phì đại (Hình 2C).

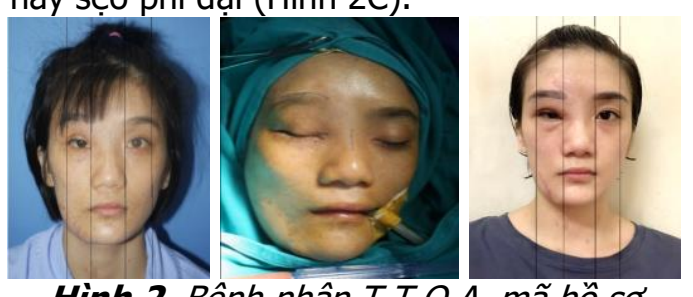

Hình 2. Bệnh nhân T.T.Q.A, mã hồ sơ 2104190733. A. Trước phẫu thuật, góc mắt trong lệch xuống dưới và ra ngoài. B. Thiết kế đường rạch da trong mổ. C. Sau phẫu thuật 3 tháng, góc mắt lên trên và vào trong. 
Trường hợp lâm sàng 2. Bệnh nhân nam 11 tuổi, tiền sử dị tật khe hở sọ mặt bẩm sinh Tessier 3, đã phẫu thuật 3 lần, sửa biến dạng khe hở môi vòm, cánh mũi. Khám hiện tại góc mắt trong phải di lệch xuống dưới và ra ngoài, tỉ lệ khoảng cách giữa góc mắt ngoài - góc mắt trong bên bệnh/bên lành là 0.9333 , ti lệ khoảng cách góc mắt trong - đường giữa mặt bên bệnh/bên lành là 1.36, không ghi nhận lộn mi, hể thống ống dẫn lệ giảm chức năng (chảy nước mắt), cánh mũi phải biến dạng, trụ mũi ngắn, môi trên co kéo (Hình 3A). Kế hoạch phẫu thuật: 1- góc mắt phải đưa lên trên $6 \mathrm{~mm}$, vào trong $4 \mathrm{~mm}$ với tạo hình chữ Z; 2- cánh mũi phải hạ thấp với vạt sống mũi và tạo hình chữ $Z$ chân cánh mũi. Vít neo tự tiêu $1.5 \times 5 \mathrm{~mm}$ (LactoSorb, WalterLorenz Surgical, USA) được sử dụng để cố định dây chằng mắt trong và cố định vạt sông mũi.

Khám lại sau 1,5 tháng góc mắt phải được cố định vững lên trên và vào trong, đối xứng góc mắt trái, tỉ lệ khoảng cách giữa góc mắt ngoài góc mắt trong bên bệnh/bên lànhlà 0.9677 , tăng so với trước phẫu thuật,ti lệ khoảng cách góc mắt trong - đường giữa mặt bên bệnh/bên lànhgiảm về 1 , không ghi nhận tình trạng co kéo, tắc ống dẫn lệ, sẹo lồi hay sẹo phì đại (Hình $3 C$ ). Hệ thống dẫn lệ cải thiện nhiều theo đánh giá chủ quan của bệnh nhân và gia đình.
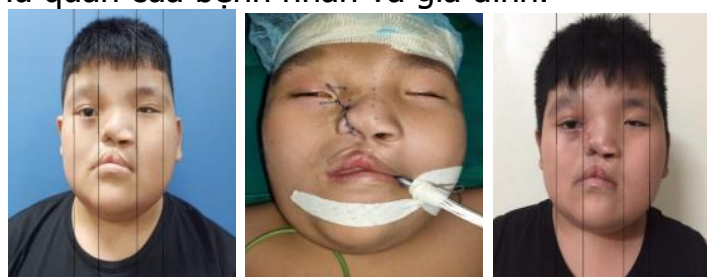

Hinh 3. Bềnh nhân N.M.H, mã hồ sơ

2107131486. A. Trước phẫu thuật, góc mắt trong di lệch, biến dạng môi trên và cánh mưi. B. Thiết kế đường rạch da trong mồ. C. Sau phẫu thuật 1.5 tháng, góc mắt được dịch chuyên lên trên và vào trong.

\section{BÀN LUÂN}

Dây chằng góc mắt trong cấu tạo từ 3 đơn vị cơ bản, có đặc điểm mô học và cơ sinh học giống với cấu tạo dây chằng hơn là gân, có vai tròneo giữ của mí mắt và duy trì hình thái góc mắt trong. Tại điểm bám tận, dây chằng góc mắt trong chia thành 3 bó. Bó trước đi ở mặt trước túi lệ, bám vào cạnh trước hố lệ và liên tục với màng xương gốc mũi. Bó trên gắn cố định vào bờ trong ổ mắt, cao hơn bám tậm bó trước 3$5 \mathrm{~mm}$. Bó sau bắt chéo túi lê đi ra sau, bám vào bờ sau hố lệ (Hình 1A). Véc tơ tổng hợp có hướng lên trền và ra sau so với bó trước, là định hướng giải phẫu quan trọng để tái tạo điểm bám dây chằng góc mắt trong để tránh tổn thương lệ quản và túi lệ. ${ }^{3}$ Bất thường điểm bám hoặc cấu trúc dây chằng góc mắt trong có thể gây ra tình trạng tắc ống dẩn lệ, trễ mi, lộn mi, nhìn mờ ảnh hưởng chức năng và chất lượng cuộc sống bệnh nhân.

Lựa chọn đường rạch da, vị trí cố định, chất liệu và hướng véc tơ trong tạo hình góc mắt trong đã được bàn luận nhiêu trong y văn, tuy nhiên tới nay vẫn chưa có đồng thuận thống

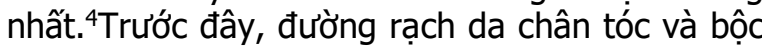
lộ rộng rãi dưới màng xương để cố định dầy chằng góc mắt trong được các tác giả lựa chọn do cung cấp trường mổ rộng rãi, dễ thao tác. Tuy nhiên, phương pháp này có đường sẹo dài, tăng nguy cơ rụng tóc, đau và dị cảm vùng da trán kéo dài, tăng nguy cơ mất máu và nhiễm trùng, tăng thời gian phẫu thuật, gây co kéo da dạng mạng nhện ở góc mắt trong, thường chỉ phù hợp khi tiến hành can thiệp đồng thời góc mắt trong và cố định xương trong chấn thương hàm mặt. Để tạo hình góc mắt trong, các tác giả đã báo cáo sử dụng các đường rạch da như $V$-W, $Z, Y-W, Y-V, V-W$ cải tiến. Tuy nhiên sẹo vùng da mũi thường có xu hướng tăng sắc tố và phì đại ở người châu Á. Park báo cáo tình trạng co kéo góc mắt trong sau tạo hình chữ Z. ${ }^{5}$ Kao và cộng sự (15) báo cáo sử dụng thiết kế dạng Y-V giảm thiểu tối đa tình trạng sẹo xấu bằng cách sử dụng vạt đẩy thay vì vạt chuyển, kéo dài đường rạch tới mi trên và mi dưới để giấu sẹo và giảm co kéo. ${ }^{6} V$ ới 2 bệnh nhân có di lệch góc mắt trong xuống dưới và ra ngoài, theo chúng tôi lựa chọn đường rạch da chữ Y sẽ khó thiết kế cân đối, cần cắt da thừa nhiêu sau khi cố định góc mắt. Chúng tôi lựa chọn đường rạch da chữ $Z$ với nguyên lý vạt chuyển, đủ chuyển góc mắt về vị trí mới và bộc lộ vị trí khoan xương cố định. Theo dõi sau 1.5 và 3 tháng cho thấy sẹo mổ liền tốt, không ghi nhận biên chứng sẹ phì đai và co kéo góc mắt tái phát, không ghi nhận tình trạng tai chó.

Về phương pháp cố định dây chằng góc mắt trong, Zhao và cộng sự sử dụng chỉ không tiêu 40 để cố định dây chằng góc mắt trong vào màng xương, tuy nhiên theo dõi xa cho thấy tình trạng di lệch góc mắt do khả năng cố định của màng xướng kém. ${ }^{7}$ Cố định dây chằng góc mắt trong bằng chỉ thép qua xương mũi đối bên là phương pháp phổ biến và hiệu quả, đạt được lực cố định tốt, tuy nhiên cần thêm một đường rạch da ở phía da mũi lành với nguy cơ sẹo xấu, kèm theo biến chứng tổn thương nhãn cầu đối bên trong quá trình khoan và luồn chỉ thép, đặc biệt 
trên người châu Á khi xương sống mũi thường thấp và nhãn cầu nhô ra trước. Bên cạnh đó, khoan 2 lỗ trên xương lệ có thành mỏng có nguy cơ gãy xương, bong điểm cố định. Elbarbary và cộng sự sử dụng chỉ thép và nẹp titan cố định đối bên để gia cố điểm bám. ${ }^{2}$ Wittkampf và cộng sự lựa chọn chỉ thép và nẹp titan cố định ở xương mũi cùng bên, luồn và chỉnh hướng chỉ thép qua lỗ nẹp titan, tuy nhiên gặp khó khăn khi cần chỉnh hướng véc tơ theo chiều dọc. ${ }^{8}$ Để giảm nguy cơ gãy xương lệ, Yu-ying Chu và cộng sự khoan 2 lỗ ở cùng bên mắt, 1 tại xương lệ theo hướng véc tơ lực và 1 tại mỏm trán xương

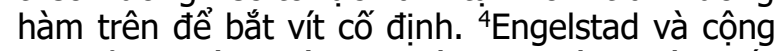
sự thử nghiệm trên 10 xác, tạo hình góc mắt trong cùng thì với kết xương hàm mặt bằng đường rạch qua cục lệ, sử dụng chỉ thép gắn thiết bị dạng mỏ neo để cố định bó sau dây chằng góc mắt, cho kết quả cố định góc mắt tốt, túi lệ và lệ quản dưới không bị tổn thương, tuy nhiên $4 / 10$ ca có biến dạng lệ quản trên, và kĩ thuật này khó áp dụng khi cần cố định góc mắt trong đơn thuần. ${ }^{3}$ Cố định góc mắt trong bằng hệ thống mỏ neo Mitek được báo cáo bởi Okazaki và Goldenberg. Hệ thống mỏ neo cố định cùng bên góc mắt, chỉ cần đường rạch da nhỏ, hạn chế bóc tách gây tổn thương mổ mềm và hiện tượng sưng nề bầm tím sau mổ, khó có thể sờ thấy từ ngoài da do mỏ neo được cố định chặt ở mặt trong của xương. Nhược điểm của hệ thổng mó neo là khó áp dụng khi tổn thương đi kèm các bất thường về xương, chi phí đắt và chưa phổ biến tại các quốc gia đang phát triền. Sharma và cộng sự báo cáo sử dụng vít tự tiêu cố định góc mắt, đầu vít được thiết kế lỗ xuyên chỉ, cố định cùng bên. Với thời gian tiêu của vít trung bình 1 năm, tác giả báo cáo kết quả theo dõi xa tốt, không có hiện tượng di lệch góc mắt tái phát, hạn chế nhược điểm của vật liệu nhân tạo kim loại, tuy nhiên nghiên cứu trên cõ mẫu nhỏ, cần nghiên cứu thêm để khẳng định. 2 bệnh nhân trong nghiên cứu của chúng tôi có nền xương cố định tốt, được lựa chọn điểm cố định cùng bên tổn thương, hạn chế đường rạch da đối diện. Vít tự tiêu có ưu điểm tạo điểm cố định tốt, không tạo phản ứng sinh học và không tạo cảm giác sờ thấy vật liệu theo thời gian. Kî thuật cố định góc mắt bằng vít tự tiêu và chỉ không tiêu được ưu tiên lựa chọn, tuy nhiên 1 trường hợp chúng tôi buộc phải sử dụng vít ti tan vì khan hiếm nguồn cung vít tự tiểu do đại dịch COVID. Ở những cơ sở sẵn có, vít tự tiêu với thiết kế lỗ luồn chỉ ở đầu vít là lựa chọn tốt, dễ thao tác và tránh tuột chỉ. Tuy nhiên chúng tôi khắc phục bằng buộc chỉchờ Prolen chắc ở thân vít, cố định vít đã quấn sẵn Prolen rồi mới cố định góc mắt. Theo chúng tôi, lựa chọn chỉ không tiêu cố định góc mắt trong kĩ thuật này có ưu điểm hơn so với sử dụng chỉ thép do chỉ nhỏ, mềm, dễ thao tác trong phâ̂u trường nhỏ nhưng vẫn đảm bảo độ bền. Kết quả theo dõi xa cho thấy góc mắt trong cố định tốt, có sự cải thiện rõ tỉ lệ khoảng cách giữa góc mắt ngoài - góc mắt trong bên bệnh/bên lành khi theo dõi sau mổ, không ghi nhận biến chứng như tắc hệ thống dẫn lệ, lộn mi, co kéo thứ phát, nhiễm trùng do chất liệu...

Tuy nhiên, nghiên cứu của chúng tôi vẫn còn một số hạn chế. Báo cáo mới chỉ dừng lại ở dạng case lâm sàng, chưa có giá trị khẳng định cao về bằng chứng khoa học. Thời gian theo dõi xa ngắn, chưa đánh giá được tác động lâu dài, đặc biệt trong quá trình tiêu chất liệu. Để khẳng định những ưu điểm của phương pháp tạo hình góc mắt trong bằng vít neo, chúng tôi cần thiết kế nghiên cứu với cỡ mẫu lớn và thời gian theo dõi xa dài hơn, tiếp tục với những đánh giá chức năng: thị lực, thị trường, hệ thống nước mắt.

\section{KẾT LUÂ̂N}

Tạo hình cố định góc mắt trong bằng vít tự tiêu khoan cùng bên tổn thương và chỉ không tiêu là phương pháp can thiệp đớn giản, xâm lấn tối thiểu, cho kết quả theo dõi gần tốt. Cần thiết kế nghiên cứu và theo dõi xa trên cõ̃ mẫu lớn để đánh giá hiệu quả và ứng dụng lâm sàng của phương pháp.

\section{TÀI LIỆ THAM KHẢO}

1. Kelly $C P$, Cohen AJ, Yavuzer R, MoreiraGonzalez A, Jackson IT. Medial Canthopexy: A Proven Technique. Ophthalmic Plastic \& Reconstructive Surgery. 2004;20(5):337-341. doi: 10.1097/ 01.IOP.0000139519.40976.28

2. Elbarbary AS, Ali A. Medial canthopexy of old unrepaired naso-orbito-ethmoidal (noe) traumatic telecanthus. Journal of Cranio-Maxillofacial Surgery. 2014; 42(2):106-112. doi:10.1016/ j.jcms. 2013.03.003

3. Engelstad ME, Bastodkar P, Markiewicz MR. Medial canthopexy using transcaruncular barb and miniplate: technique and cadaver study. International Journal of Oral and Maxillofacial Surgery. 2012;41(10):1176-1185. doi:10.1016/ j.ijom.2012.06.019

4. Chu Y-Y, Lim E, Liao H-T. Ipsilateral transnasal medial canthopexy to correct secondary telecanthus after naso-orbito-ethmoid fracture. Journal of Plastic, Reconstructive \& Aesthetic Surgery. 2020;73(5):934-941. doi:10.1016/ j.bjps.2020.01.007

5. Park JI. Modified Z-Epicanthoplasty in the Asian Eyelid. Archives of Facial Plastic Surgery. 
2000;2(1): 43-47. doi:10.1001/archfaci.2.1.43

6. Kao $\mathbf{Y}-\mathbf{S}$, Lin $\mathbf{C}-\mathbf{H}$, Fang $\mathbf{R}-\mathbf{H}$. Epicanthoplasty with Modified Y-V Advancement Procedure: Plastic and Reconstructive Surgery. 1998;102(6):18351841. doi:10.1097/00006534-199811000-00004

7. Zhao Y-Q, Luo D-A. Modified Y-V Epicanthoplasty With Raised Medial Canthus in the Asian Eyelid.
Arch Facial Plast Surg. 2010;12(4). doi:10.1001/ archfacial.2010.51

8. Wittkampf ARM, Mourits MPh. A simple method for medial canthal reconstruction. International Journal of Oral and Maxillofacial Surgery. 2001;30(4):342-343. doi:10.1054/ ijom.2001.0060

\section{MÔ HİNH BÊNNH TÂT TAI KHOA HồI SỨC CẤP CỨU BÊNH VIÊ̂N ĐA KHOA QUỐC TẾ VINMEC PHÚ QUỐC NĂM 2019}

\section{Hoàng Văn Hải*, Lê Thị Thu Hiền*, Vũ Đức Định*}

\section{TÓM TẮT}

Mục tiêu: Mô tả mô hình bênh tật tại khoa HSCC bệnh viện ĐKQT Vinmec Phú Quốc từ 1.2019-12.2019. Phương pháp : Nghiên cứu mô tả ca bệnh hồi cứu. Kết quả: Lướng BN có xu hướng tăng cao vào giai đoạn từ tháng 9 đến tháng 3 sang năm. Tỷ lệ nam/ nữ: $52,3 \%$ so với $47,7 \%$. BN trẻ em chiếm $30,2 \%$. Người lớn 69,8\%). BN là khách du lịch: $62.45 \%$ trong đó số BN người nước ngoài chiếm $38.5 \%$. Nhóm bệnh lý chính: Rối loạn tiêu hóa (62,2\%); Chấn thương các loại $(20,02 \%)$; Sốt virus $(11,75 \%)$ và bệnh lý hô hấp $(8,34 \%)$. Số BN nặng cần HSCC chiếm $10.5 \%$. Một số yếu tố ảnh hưởng đến mô hình bệnh tật $B N$ vào cấp cứu tại BVĐK QT VMPQ: (i). Khách du lịch trong và ngoài nước; (ii). Thói quen, tập quán sinh hoạt đi lại của dân đia phương và của khách du lịch; (iii). Mối trường tại $P Q$ với đặc thù là khí hậu biển, chia hai mùa mưa và mùa khô rõ̃ rệt. Kết luận: Hệ thống y tế trên Đảo cần chuẩn bị đầy đủ các phương tiện cấp cứu, thuốc men phù hợp với mô hình bênh tật tại địa phương. Xây dựng mô hình hệ thống cấp cứu tiền viện - HSTC tai chố - Vân chuyển BN về đất liền an toàn.

Tư khóa: Mô hình bệnh tật, khoa Hồi sức cấp cứu, Bệnh viện ĐKQT Vinmec, Phú Quốc.

\section{SUMMARY \\ TO DESCRIBE THE DISEASE PATTERN AT THE ED OF VINMEC PHU QUOC INTERNATIONAL GENERAL HOSPITAL, 2019}

Objective: To describe the disease pattern at the ED of Vinmec Phu Quoc International General Hospital from January 1, 2019 to deacember, 2019. Methods: A retrospective descriptive study. Results: The number of patients tends to increase in the period from September to March next year. Male/Female Ratio: $52.3 \%$ vs $47.7 \%$. Children accounted for $30.2 \%$. Adults $69.8 \%$ ). Patients are tourists: $62.45 \%$ of which foreigner account for $38.5 \%$. The main group of diseases: Digestive disorders (62.2\%); Injuries of

*Bệnh viện ĐK QT Vinmec Phú Quốc Chịu trách nhiệm chính: Vũ Đức Định Email: drvuducdinh@gmail.com Ngày nhận bài: $11 / 8 / 2021$

Ngày phản biện khoa học: 15/9/2021 Ngày duyệt bài: 4/10/2021 all kinds (20.02\%); Viral fever $(11.75 \%)$ and respiratory disease (8.34\%). The number of severe patients requiring intensive care accounts for $10.5 \%$. Some factors affect the disease pattern of patients entering the emergency department at VMPQ General Hospital: (i). Domestic and foreign tourists; (ii). Habits, living habits of local people and tourists; (iii). The environment in $\mathrm{PQ}$ is characterized by a marine climate, divided into two distinct rainy and dry seasons. Conclusion: The medical system on the Island needs to be fully prepared with emergency facilities and medicines suitable to the local disease pattern. Building a model of a pre-hospital emergency system - on-site medical care - Transporting patients to the mainland safely.

Keywords: Disease pattern, ED, Vinmec Phu Quoc International General Hospital

\section{I. ĐẶT VẤN ĐỀ}

Phú Quốc $(\mathrm{PQ})$ nằm ở phía tây nam và là hòn đảo lớn nhất Việt Nam có diện tích 589.27 km², dân số 179499 người (2019). Du lịch là mũi nhọn kinh tế lớn nhất tại $\mathrm{PQ}$ với tổng lượng khách hớn 6 triệu/năm, nguổn khách đến từ khắp nơi trên thế giới (châu Âu, Mỹ, Trung Quốc, Nhật Bản...).

Bệnh viện Đa khoa quốc tế (ĐKQT) Vinmec PQ hàng năm tiếp nhận từ 10000 -15000 trường hợp bệnh nhân vào cấp cứu từ đối tượng khách du lịch và người dân trên Đảo với các mặt bệnh chủ yếu là sốt, rối loạn tiêu hóa, chấn thướng, cấp cứu ngoại bụng, lồng ngực... cùng các loại bệnh lý mang tính đặc thù của nhiều quốc gia.

$P Q$ đang trên đà phát triển về mọi mặt. Lượng dân số và khách du lịch gia tăng sẽ đòi hỏi công tác $Y$ tế trong đó có hôi sức cấp cứu (HSCC) phải được chuẩn bị đây đủ để đáp ứng nhu câu tại chỗ. Việc tìm hiểu mô hình bệnh lý cấp cứu là cần thiết cho công tác chuẩn bị nhân lực, trang thiết bị, thuốc men phù hợp. Vì vậy chúng tôi tiến hành nghiên cưu: "Mô hình bênh tật tại khoa HSCC bênh viện ĐKQT Vinmec Phú Quốc năm 2019" nhằm mục tiêu: Mô tả mô hình bệnh tật tại khoa HSCC bệnh viện ĐKQT Vinmec Phú Quốc từ 1.2019-12.2019. 